\title{
Papillon-Lefèvre syndrome: a series of five cases among siblings
}

Zyad M. AlBarrak ${ }^{1 *}$, Adel S. Alqarni², Elna P. Chalisserry ${ }^{3}$ and Sukumaran Anil ${ }^{2}$

\begin{abstract}
Background: Papillon-Lefèvre syndrome is a rare autosomal recessive disorder characterized by palmoplantar hyperkeratosis and aggressively progressing periodontitis leading to premature loss of deciduous and permanent dentition. The etiopathogenesis of the syndrome is relatively obscure, and immunologic, genetic, or possible bacterial etiologies have been proposed.

Case presentation: A series of five cases of Papillon-Lefèvre syndrome among the siblings in a family is presented here: a 3-year-old Arab girl, a 4-year-old Arab boy, a 11-year-old Arab boy, a 12-year-old Arab boy, and a 14-year-old Arab boy. The patients presented with severe gingival inflammation and mobility of teeth. The clinical manifestations were typical of Papillon-Lefèvre syndrome and the degree of involvement of the oral and skin conditions varied among them.

Conclusions: This case series stresses the consanguinity in the family as an etiologic factor. All siblings in the family were affected with Papillon-Lefèvre syndrome which makes this a rare case. A multidisciplinary approach with the active participation of a dental surgeon, dermatologist, and pediatrician is essential for the management of cases of Papillon-Lefèvre syndrome.
\end{abstract}

Keywords: Papillon-Lefèvre syndrome, Consanguinity, Periodontitis, Premature tooth loss, Cathepsin C, Gene mutation, Hyperkeratosis, Palmoplantar keratosis

\section{Background}

Papillon-Lefèvre syndrome (PLS) is a rare autosomal recessive heterogeneous disorder, which is characterized by palmoplantar hyperkeratosis, early loss of primary and permanent teeth, and associated calcification of the dura mater [1]. The onset of disease usually coincides with the eruption of primary teeth. Boys and girls are equally affected, with no racial predominance [2]. The onset of the cutaneous lesion of PLS may appear at birth or at 1 to 2 months of age, but most commonly appears between the age of 6 months and 4 years which coincides with the eruption of primary teeth [3]. Associated features may include intracranial calcifications, susceptibility to bacterial infections, and mental retardation [4].

The exact etiology of PLS is still obscure; however, microbiologic, immunologic, and genetic factors have all been linked to the development of the syndrome. The disorder can be hereditary, acquired, or associated with

\footnotetext{
* Correspondence: ksucod@gmail.com

${ }^{1}$ King Abdulaziz Medical City, Ministry of Health, Riyadh, Saudi Arabia Full list of author information is available at the end of the article
}

other syndromes. PLS is autosomal recessive, and consanguinity has been demonstrated in 20 to $40 \%$ of patients [5]. Earlier reports have described PLS in children of consanguineously married parents $[6,7]$. If both parents are carriers of the defective gene there is a $25 \%$ risk for their children to be affected [8].

Consanguineous marriage is a cultural practice with ancient roots, and $20 \%$ of the world's population currently lives in communities that prefer this form of marriage [9]. Arab countries have the highest rates (20 to $50 \%$ ) of consanguineous marriage in the world [10]. An etiological link to Cathepsin C (CTSC) gene mutations leading to a deficiency of cathepsin $C$ enzymatic activity has been identified [11, 12]. Aggregatibacter actinomycetemcomitans was reported to have a significant role in the progression of periodontal involvements. Other microbial agents including Porphyromonas gingivalis, Fusobacterium nucleatum, and Treponema denticola have also been suggested to have causal effects [13]. PLS is characterized by aggressively progressive periodontitis accompanied by palmoplantar hyperkeratosis. In some 
cases, the hyperkeratosis may spread to the knees, elbows, back, and fingers [1]. Disorders such as abscesses of the skin, liver, kidneys, and brain, as well as dural calcification have also been reported [14, 15].

The oral findings of PLS are hypermobility, drifting, migration, and exfoliation of teeth without any signs of root resorption. The periodontitis causes premature loss of deciduous and permanent teeth, often leaving the patient edentulous in adolescence [16]. The gingiva gets inflamed with the eruption of the primary teeth. Subsequently a rapid destruction of periodontium occurs and most affected children experience premature loss of their primary teeth. The gingiva resumes normal appearance after exfoliation of the primary dentition. The aggressive inflammatory periodontal process then re-triggers itself after the eruption of the permanent teeth, and in general all or most of the permanent dentition is lost during the teenage years [7]. Radiographic features are characterized by generalized loss of alveolar bone [3] and intracranial calcification [17]. A well-documented case series of PLS among five siblings in a family is presented. The oral and cutaneous manifestations and current treatment modalities are discussed.

\section{Case presentation}

The case series were seen at an out-patient department. The clinical manifestations were typical of PLS and the degree of involvement of the oral and skin conditions varied among the siblings (Figs. 1, 2, 3, 4, 5, 6, and 7). The patient details and clinical features are depicted in Table 1. The parents of these five children are first cousins and the possibility of consanguinity was established as a probable etiologic factor. Since all the patients were otherwise healthy and their medical records did not show any hematological abnormalities, the cases were referred to the King Faisal Specialty Hospital, Riyadh, Saudi Arabia. The center has a unit for managing cases of PLS, which coordinates dental, dermatology, and genetic disorder research and management due to the high number of cases in Saudi Arabia. It acts as a national coordination unit and gives advice and follow up on cases of PLS.

Early extraction of periodontally involved permanent teeth has been considered to be a mode of treatment to preserve alveolar bone [18, 19]. Treatment modalities other than extraction have been attempted in patients with PLS. Local debridement and/or systemic antibiotics alone or in combination have shown transient improvement of the condition [20]. Since there is no definitive treatment for cases of PLS, rehabilitation of the dentition is done considering factors such as age and psychosocial impact.
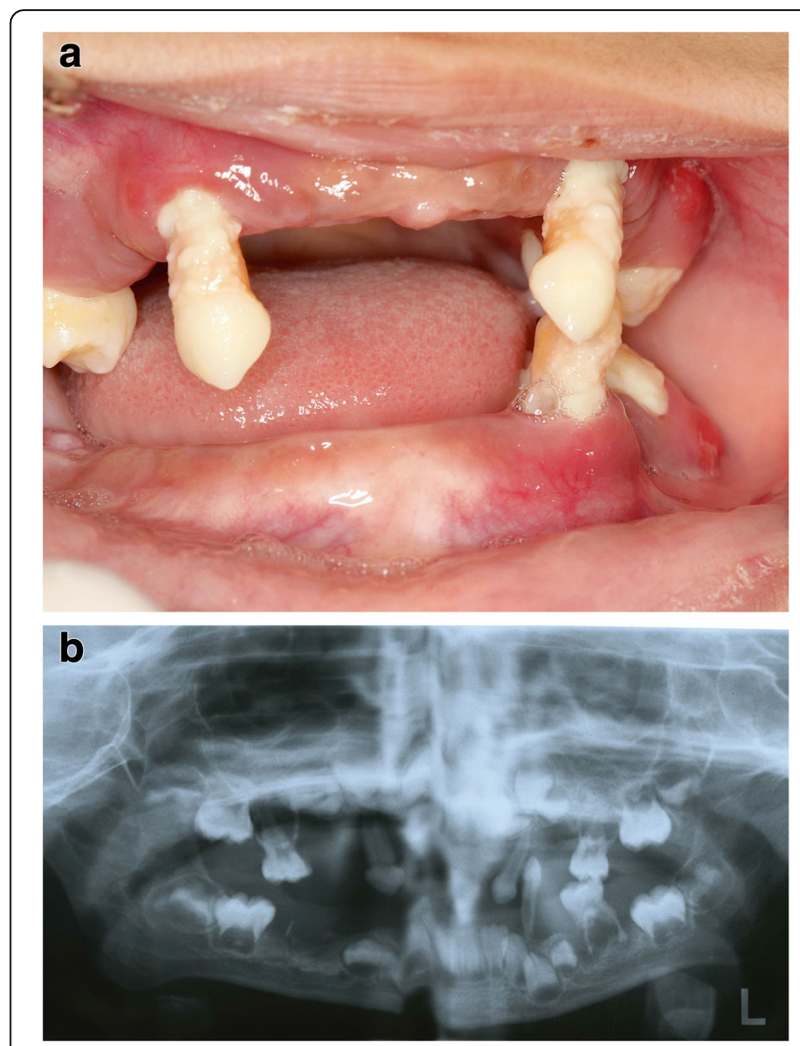

Fig. 1 Case 1. a Clinical appearance of the deciduous teeth, note the exfoliated primary teeth, gingivitis, and plaque accumulation. b Panoramic radiograph showing bone loss and migrated teeth with bone loss

\section{Case 1}

A 3-year-old Arab girl was examined as part of an investigation of her eldest brother's case. All her anterior and most of her posterior primary teeth were lost. There was inflammation of her gingiva with plaque accumulation in her teeth (Fig. 1 and Table 1). Her palms and soles appeared normal. However, thickening of the skin was observed in her knees, elbows, and toes. Plaque was present in almost all her remaining deciduous teeth. Basic Periodontal Examination (BPE) using World Health Organization (WHO) 621 probe showed a code 4 in her remaining teeth [21]. Scaling was performed in our clinic and her parents were advised to maintain her oral hygiene. Home care measures were emphasized. Temporary space maintainers were fabricated and periodic follow up was advised.

\section{Case 2}

A 4-year-old Arab boy presented to our clinic with exfoliated maxillary right central and lateral incisor. Gingivitis and plaque accumulation were present in his remaining teeth. The BPE showed a code between 3 

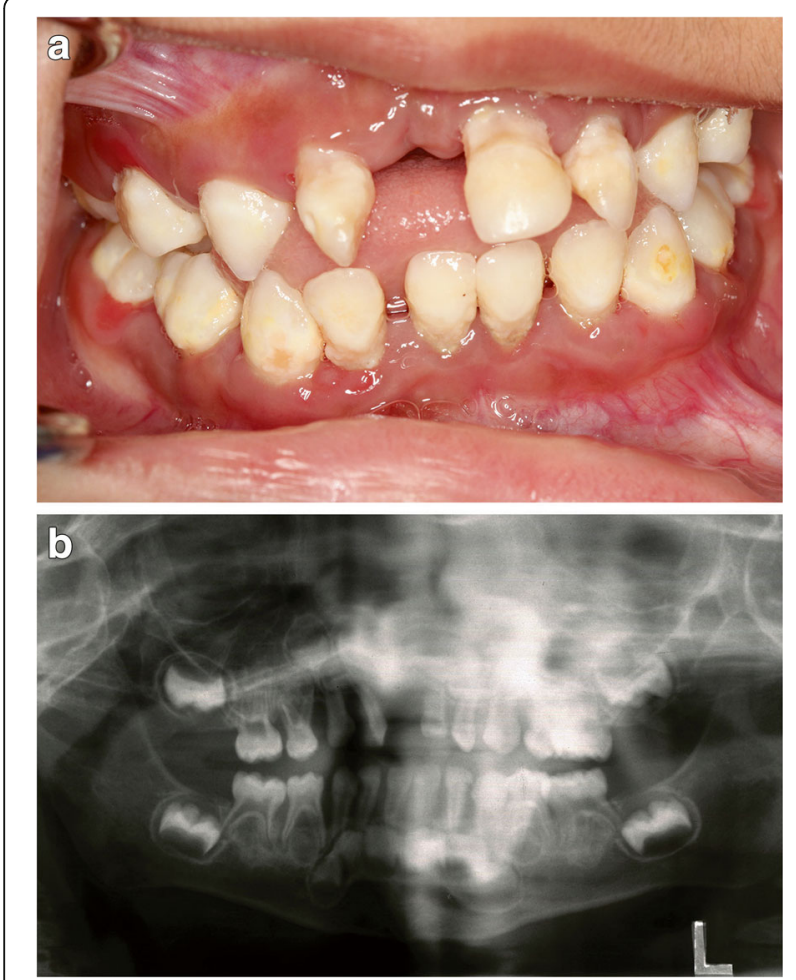

Fig. 2 Case 2. a Intraoral appearance with gingival inflammation, plaque accumulation, migration of teeth. $\mathbf{b}$ Panoramic radiograph showing bone destruction and interdental spacing

and 4 in his remaining teeth. There was alveolar bone destruction around all erupted and erupting dentition. Keratosis of his palms and soles was present at a mild degree (Fig. 2 and Table 1). Scaling was performed in our clinic. We advised that he had periodic oral hygiene measures. A temporary denture was fabricated to wear during the daytime.

\section{Case 3}

An 11-year-old Arab boy presented with mobile protruded and migrated maxillary and mandibular anterior

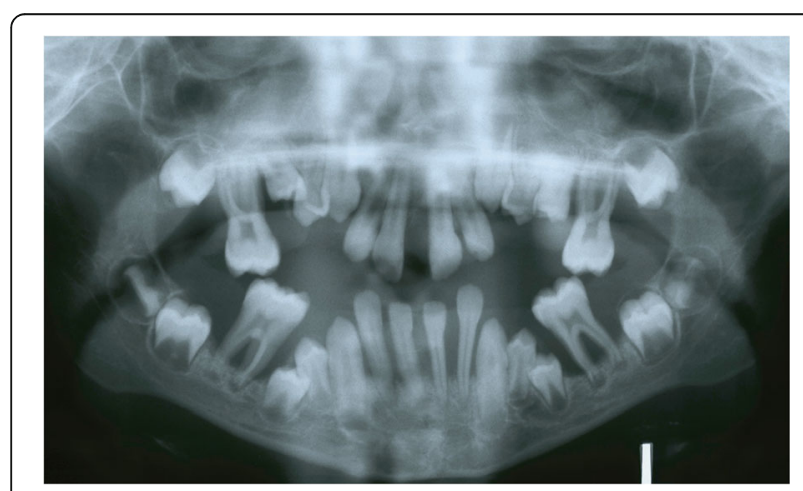

Fig. 3 Case 3. Panoramic radiograph showing severe periodontal destruction and migration of teeth
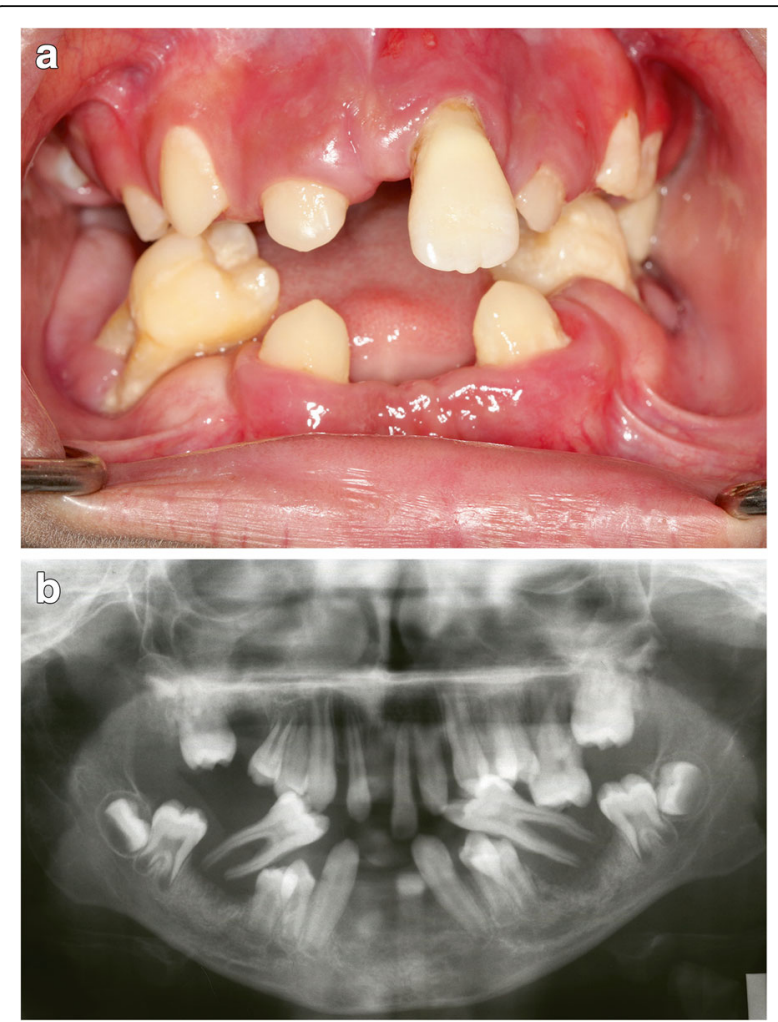

Fig. 4 Case 4. a Severe gingivitis with periodontal destruction and migration of permanent molars. $\mathbf{b}$ Panoramic radiograph showing severe periodontal destruction, note the migration and floating of the lower first molars

teeth. All his primary teeth were lost. There was severe bone destruction around his permanent teeth. His molars were all mobile with less than one third bone support. A BPE code 4 was recorded in all his molars and incisors. There was bleeding from his gingiva with halitosis (Fig. 3 and Table 1). He had dermatologic manifestations such as keratinized skin in his joints, palms, and soles. Scaling was done in our clinic to remove all debris, plaque, and calculus. Periodic scaling (monthly) was advised and strict oral care measures were advised.

\section{Case 4}

A 12-year-old Arab boy presented with multiple exfoliated teeth. His oral hygiene was relatively better with gingival enlargement around erupting teeth. Most of his permanent anterior teeth were lost with severe bone destruction around his remaining teeth (Fig. 4, Table 1). A periodontal examination recorded a score of 4 (deep pocket) in his molars and incisors. His lower molars appeared floating without any bone support. There was severe palmar plantar keratosis with keratinization of 

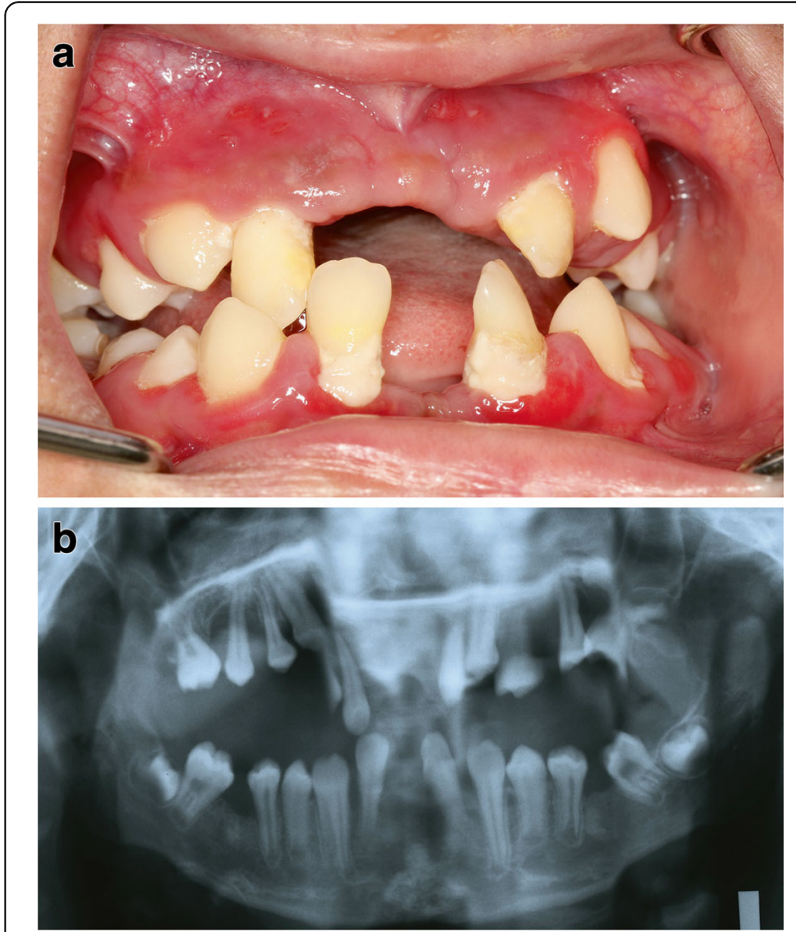

Fig. 5 Case 5. a Intraoral appearance with loss of permanent anterior from both jaws, severe inflammation, and enlargement of the gingiva. b Panoramic radiograph showing severe destruction of the alveolar bone and loss of permanent anterior teeth

the dorsal surface of his hands. His molars were extracted, transitional dentures were given, and a followup regimen was advised.

\section{Case 5}

A 14-year-old Arab boy, the eldest brother of these patients, was the one who presented for treatment: the replacing of his anterior teeth which were exfoliated. On radiographic examination severe bone destruction was noticed around his remaining teeth (Fig. 5). Periodontal recording using the BPE index showed a score of 4 for most of his remaining teeth. Associated dermatologic findings were conclusive of PLS, such as sever palmar plantar keratosis which affected the dorsal surface of his palms (Figs. 6 and 7, Table 1). Scaling and root planning was performed in his first visit and he was kept on a strict oral hygiene regimen. A temporary partial denture was fabricated and he was scheduled for implant therapy at a later stage.

\section{Discussion}

The etiopathogenesis of the syndrome is relatively obscure and immunologic, genetic, or possible bacterial etiologies have been proposed [22]. The incidence in
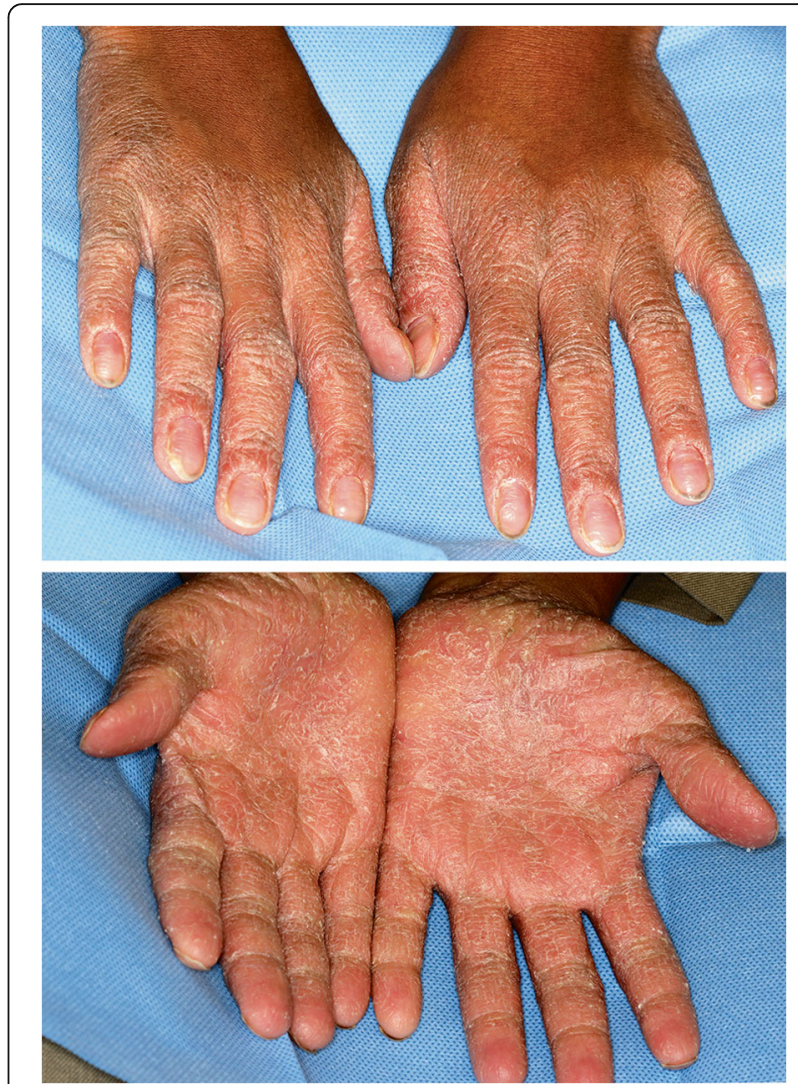

Fig. 6 Hyperkeratotic lesions on the palms and the dorsal surface (Case 5)

Saudi Arabia is higher compared with other parts of the world which may be attributed to cluster marriages $[2,3]$. The severe periodontal destruction seen in PLS may be the result of loss of function mutation in the CTSC gene resulting in the dysregulation of localized polymorphonuclear leucocytes in the periodontal tissues [23].

One third of the cases of PLS reported in the literature had consanguineous parents $[8,16,24]$. PLS shows an autosomal recessive pattern and there is $25 \%$ chance for the offspring getting affected from phenotypically healthy parents who carry the autosomal gene [25]. In the present case series all the children (five siblings) were affected which makes this a rare case. Most of the cases reported so far had two siblings affected [7, 26-28] except for a few cases in which three or four siblings were affected [29-33]. Mutations in the CTSC gene have been reported to result in PLS and the complete absence of cathepsin $\mathrm{C}$ activity is required in order to develop the clinical phenotype of PLS [25].

A possible bacterial etiology has also been proposed and it is believed that Aggregatibacter actinomycetemcomitans, Porphyromonas gingivalis, Fusobacterium nucleatum, and 


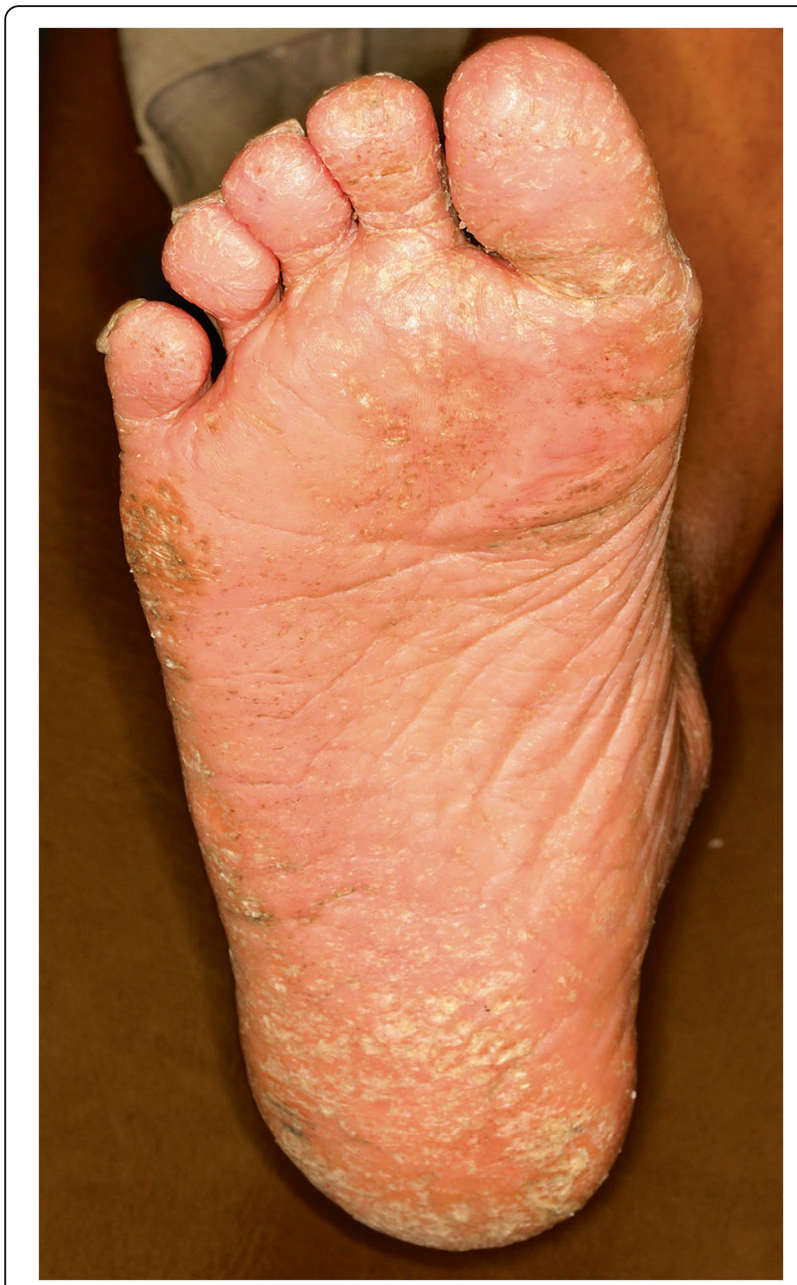

Fig. 7 Hyperkeratotic lesions on the soles (Case 5)

Prevotella intermedia may be among the organisms involved in periodontal breakdown [34]. General periodontal treatment modalities usually fail in patients with PLS, and the rapid progression of periodontitis results in severe loss of alveolar bone $[35,36]$. Treatment modalities such as systemic and local antibiotic treatment, and synthetic retinoids have been tried with limited success [37]. Prolonged use of oral retinoids has been shown to be beneficial in preventing exfoliation of permanent teeth in children [38]. The rapid destruction of alveolar bone around the primary and permanent teeth results in atrophic jaws. Hence, the oral rehabilitation of these cases is challenging and implant-supported overdentures are generally recommended in edentulous patients with PLS [39].

\section{Conclusions}

- PLS is an autosomal recessive genetic disorder characterized by palmoplantar hyperkeratosis
Table 1 Patient details and clinical findings

\begin{tabular}{|c|c|c|c|c|c|c|}
\hline \multirow[t]{2}{*}{ Variables } & & \multicolumn{5}{|c|}{ Cases } \\
\hline & & 1 & 2 & 3 & 4 & 5 \\
\hline Gender & & $\mathrm{F}$ & M & M & M & M \\
\hline Age (years) & & 3 & 4 & 11 & 12 & 14 \\
\hline \multirow{6}{*}{$\begin{array}{l}\text { Periodontal } \\
\text { manifestations }\end{array}$} & Gingivitis & + & + & + & + & + \\
\hline & $\begin{array}{l}\text { Periodontitis; Basic Periodontal } \\
\text { Examination (BPE) Score }\end{array}$ & 4 & 4 & 4 & 4 & 4 \\
\hline & Primary teeth loss & + & + & + & + & + \\
\hline & Permanent teeth loss & - & - & - & + & + \\
\hline & Alveolar bone resorption & + & + & + & + & + \\
\hline & Halitosis & + & + & + & + & + \\
\hline \multirow[t]{5}{*}{ Skin manifestations } & Palmoplantar hyperkeratosis & - & + & + & + & + \\
\hline & Elbows & + & + & + & + & + \\
\hline & Knees & + & + & + & - & + \\
\hline & Toes & + & + & + & - & - \\
\hline & Dorsal fingers & - & - & + & + & - \\
\hline
\end{tabular}

+ present, - absent, $F$ female, $M$ male

associated with severe early-onset periodontitis and premature loss of primary and permanent teeth.

- Even though the occurrence of PLS among siblings is documented this is the first case where all five siblings were affected.

- There is no definitive treatment for PLS cases. Symptomatic management is followed.

- A multidisciplinary approach with the active participation of a dental surgeon, dermatologist, and pediatrician is essential for the management of case of PLS.

\section{Abbreviations}

BPE, Basic Periodontal Examination; CTSC, Cathepsin C; PLS, Papillon-Lefèvre syndrome; WHO, World Health Organization

\section{Acknowledgements}

Not applicable.

\section{Funding}

No funding involved.

\section{Availability of data and materials Not applicable.}

\section{Authors' contributions}

$\mathrm{ZA}, \mathrm{AA}$, and SA have seen the patients and diagnosed the cases. EC did the radiographic documentation and literature search. SA and EC wrote the draft and edited the manuscript. All authors read and approved the manuscript.

\section{Competing interests}

The authors declare that they have no competing interests.

\section{Consent for publication}

Written informed consent was obtained from the patients' legal guardians for publication of this case report and any accompanying images. A copy of the written consent is available for review by the Editor-in-Chief of this journal. 


\section{Ethics approval and consent to participate}

Not applicable.

\author{
Author details \\ ${ }^{1}$ King Abdulaziz Medical City, Ministry of Health, Riyadh, Saudi Arabia. \\ 2Department of Preventive Dental Sciences, College of Dentistry, Prince \\ Sattam Bin Abdulaziz University, 153, Alkharj 11942, Riyadh, Saudi Arabia. \\ ${ }^{3}$ Department of Maxillofacial Surgery and Diagnostic Sciences, College of \\ Dentistry, Jazan University, Jazan 82943, Saudi Arabia.
}

Received: 10 April 2016 Accepted: 1 September 2016 Published online: 22 September 2016

\section{References}

1. Gorlin RJ, Sedano H, Anderson VE. The syndrome of palmar-plantar hyperkeratosis and premature periodontal destruction of the teeth. A clinical and genetic analysis of the Papillon-Lefèvre syndrome. J Pediatr. 1964;65:895-908.

2. Hattab FN, Rawashdeh MA, Yassin OM, al-Momani AS, al-Ubosi MM. Papillon-Lefèvre syndrome: a review of the literature and report of 4 cases. J Periodontol. 1995;66(5):413-20.

3. Dhanrajani PJ. Papillon-Lèfevre syndrome: clinical presentation and a brief review. Oral Surg Oral Med Oral Pathol Oral Radiol Endod. 2009;108(1):e1-7.

4. Almuneef $\mathrm{M}, \mathrm{Al}$ Khenaizan $\mathrm{S}, \mathrm{Al}$ Ajaji $\mathrm{S}, \mathrm{Al}$-Anazi A. Pyogenic liver abscess and Papillon-Lefèvre syndrome: not a rare association. Pediatrics. 2003; 111(1):e85-8.

5. Zhang Y, Lundgren T, Renvert S, Tatakis DN, Firatli E, Uygur C, Hart PS, Gorry MC, Marks JJ, Hart TC. Evidence of a founder effect for four cathepsin C gene mutations in Papillon-Lefèvre syndrome patients. J Med Genet. 2001; 38(2):96-101.

6. Khan FY, Jan SM, Mushtaq M. Papillon-Lefèvre syndrome: Case report and review of the literature. J Indian Soc Periodontol. 2012;16(2):261-5.

7. Rathod VJ, Joshi NV. Papillon-Lefèvre syndrome: A report of two cases. J Indian Soc Periodontol. 2010;14(4):275-8.

8. Hart TC, Shapira L. Papillon-Lefèvre syndrome. Periodontol 2000. 1994;6:88-100.

9. Modell B, Darr A. Science and society: genetic counselling and customary consanguineous marriage. Nat Rev Genet. 2002;3(3):225-9.

10. Vardi-Saliternik R, Friedlander $Y$, Cohen T. Consanguinity in a population sample of Israeli Muslim Arabs, Christian Arabs and Druze. Ann Hum Biol. 2002;29(4):422-31.

11. Hart TC, Hart PS. Genetic studies of craniofacial anomalies: clinical implications and applications. Orthod Craniofac Res. 2009;12(3):212-20.

12. Kurban M, Wajid M, Shimomura Y, Bahhady R, Kibbi AG, Christiano AM. Evidence for a founder mutation in the cathepsin $C$ gene in three families with Papillon-Lefèvre syndrome. Dermatology. 2009;219(4):289-94.

13. Stabholz A, Taichman NS, Soskolne WA. Occurrence of Actinobacillus actinomycetemcomitans and anti-leukotoxin antibodies in some members of an extended family affected by Papillon-Lefèvre syndrome. J Periodontol. 1995;66(7):653-7.

14. Kanthimathinathan HK, Browne F, Ramirez R, McKaig S, Debelle G, Martin J, Chapple IL, Kay A, Moss C. Multiple cerebral abscesses in Papillon-Lefèvre syndrome. Childs Nerv Syst. 2013;29(8):1227-9.

15. Morgan RD, Hannon E, Lakhoo K. Renal abscess in Papillion-Lefèvre syndrome. Pediatr Surg Int. 2011;27(12):1381-3.

16. Ullbro C, Crossner CG, Nederfors T, Alfadley A, Thestrup-Pedersen K. Dermatologic and oral findings in a cohort of 47 patients with PapillonLefèvre syndrome. J Am Acad Dermatol. 2003;48(3):345-51.

17. Reyes VO, King-Ismael D, Abad-Venida L. Papillon-Lefèvre syndrome. Int J Dermatol. 1998;37(4):268-70.

18. Shapira J, Eidelman E, Fuks A, Hacham-Zadeh S. Treatment of PapillonLefèvre syndrome with chemotherapy: report of cases. Spec Care Dentist. 1985;5(2):71-4

19. Van Dyke TE, Taubman MA, Ebersole JL, Haffajee AD, Socransky SS, Smith DJ, Genco RJ. The Papillon-Lefèvre syndrome: neutrophil dysfunction with severe periodontal disease. Clin Immunol Immunopathol. 1984;31(3):419-29.

20. Preus HR. Treatment of rapidly destructive periodontitis in Papillon-Lefèvre syndrome. Laboratory and clinical observations. J Clin Periodontol. 1988; 15(10):639-43.

21. Clerehugh $V$, Tugnait A. Diagnosis and management of periodontal diseases in children and adolescents. Periodontol 2000. 2001;26:146-68.
22. Dalgic B, Bukulmez A, Sari S. Eponym: Papillon-Lefèvre syndrome. Eur J Pediatr. 2011;170(6):689-91.

23. Ryu OH, Choi SJ, Firatli E, Choi SW, Hart PS, Shen RF, Wang G, Wu WW, Hart TC. Proteolysis of macrophage inflammatory protein-1alpha isoforms LD78beta and LD78alpha by neutrophil-derived serine proteases. J Biol Chem. 2005;280(17):17415-21.

24. Haneke E. The Papillon-Lefèvre syndrome: keratosis palmoplantaris with periodontopathy. Report of a case and review of the cases in the literature. Hum Genet. 1979:51(1):1-35.

25. Toomes C, James J, Wood AJ, Wu CL, McCormick D, Lench N, Hewitt C, Moynihan L, Roberts E, Woods CG, et al. Loss-of-function mutations in the cathepsin $C$ gene result in periodontal disease and palmoplantar keratosis. Nat Genet. 1999;23(4):421-4.

26. Mercy P, Singh A, Ghorpade AK, Das M, Upadhyay A. Papillon-Lefèvre syndrome: two siblings, one developing liver abscess. Indian J Dermatol. 2013;58(5):410.

27. Mohan RS, Verma S. Haim Munk syndrome: report of two siblings of northern India treated with acitretin. Indian J Dermatol Venereol Leprol. 2011;77(2):252.

28. Sharma A, Kaur G, Sharma A. Papillon-Lefèvre syndrome: A case report of 2 affected siblings. J Indian Soc Periodontol. 2013;17(3):373-7.

29. Fayed NA, Nasif A, Younis AS, Ayoub AF. Hyperkeratosis palmoplantaris with periodontosis. "Papillon-Lefèvre syndrome". Report of three cases in the same family. Egypt Dent J. 1984;30(1):77-84.

30. Idon PI, Olasoji HO, Fusami MA. Papillon-Lefèvre syndrome: review of literature and report of three cases in the same family. Niger Postgrad Med J. $2015 ; 22(1): 75-82$.

31. Keskin-Yildirim Z, Simsek-Derelioglu S, Kantarci M, Yilmaz Y, Buyukavci M. Papillon-Lefèvre syndrome: report of three cases in the same family. Turk J Pediatr. 2012;54(2):171-6.

32. Angel TA, Hsu S, Kornbleuth SI, Kornbleuth J, Kramer EM. Papillon-Lefèvre syndrome: a case report of four affected siblings. J Am Acad Dermatol. 2002;46(2 Suppl Case Reports):S8-10.

33. Kellum RE. Papillon-Lefèvre syndrome in four siblings treated with etretinate. A nine-year evaluation. Int J Dermatol. 1989;28(9):605-8.

34. Albandar JM, Khattab R, Monem F, Barbuto SM, Paster BJ. The subgingival microbiota of Papillon-Lefèvre syndrome. J Periodontol. 2012:83(7):902-8.

35. Kleinfelder JW, Topoll HH, Preus HR, Muller RF, Lange DE, Bocker W. Microbiological and immunohistological findings in a patient with PapillonLefèvre syndrome. J Clin Periodontol. 1996;23(11):1032-8.

36. Eronat N, Ucar F, Kilinc G. Papillon Lefèvre syndrome: treatment of two cases with a clinical microbiological and histopathological investigation. J Clin Pediatr Dent. 1993;17(2):99-104.

37. Kressin S, Herforth A, Preis S, Wahn V, Lenard HG. Papillon-Lefèvre syndrome - successful treatment with a combination of retinoid and concurrent systematic periodontal therapy: case reports. Quintessence Int. 1995;26(11): 795-803.

38. Lee MR, Wong LC, Fischer GO. Papillon-Lefèvre syndrome treated with acitretin. Australas J Dermatol. 2005;46(3):199-201.

39. Ahmadian L, Monzavi A, Arbabi R, Hashemi HM. Full-mouth rehabilitation of an edentulous patient with Papillon-Lefèvre syndrome using dental implants: a clinical report. J Prosthodont. 2011;20(8):643-8.

\section{Submit your next manuscript to BioMed Central and we will help you at every step:}

- We accept pre-submission inquiries

- Our selector tool helps you to find the most relevant journal

- We provide round the clock customer support

- Convenient online submission

- Thorough peer review

- Inclusion in PubMed and all major indexing services

- Maximum visibility for your research

Submit your manuscript at www.biomedcentral.com/submit 